Int. J. Electrochem. Sci., 13 (2018) 10217 - 10232

International Journal of

ELECTROCHEMICAL

SCIENCE

www.electrochemsci.org

\title{
Effect of the Particle Size of 316L Stainless Steel on the Corrosion Characteristics of the Steel Fabricated by Selective Laser Melting
}

\author{
Wei Chen ${ }^{1}$, Guangfu Yin ${ }^{1, *}$, Zhongbing Huang ${ }^{1}$, Zai Feng $^{2}$ \\ ${ }^{1}$ College of Materials Science and Engineering, Sichuan University, Chengdu, 610065, China \\ ${ }^{2}$ Sichuan Hengchuang Bolian Technology Co., Ltd, Chengdu, 610044, China \\ *E-mail: nic0700@ scu.edu.cn
}

doi: $10.20964 / 2018.11 .11$

Received: 10 June 2018 / Accepted: 6 August 2018 / Published: 1 October 2018

The corrosion characteristics of 316L stainless steel (SS316L) fabricated by selective laser melting (SLM) in a $6.0 \mathrm{wt} . \% \mathrm{FeCl}_{3}$ solution was investigated in this study. To analyse the relationship between the corrosion factor and powder feedstock, three samples were made by SLM with three particle sizes, and their potentiodynamic polarization curve were measured using a CHI660E electrochemical working station in a $6.0 \mathrm{wt} . \% \mathrm{FeCl}_{3}$ solution at $25{ }^{\circ} \mathrm{C}$. The microstructure was investigated by optical microscopy (OM) and scanning electron microscopy (SEM). Corrosion products analyses were performed using an X-ray energy dispersion spectroscopy (EDS) detection system. The results showed that the SLM samples prepared with fine powder possessed the best surface quality with a much lower porosity and without un-melted powder particles. Compared with the SLM samples from the coarse powder and raw powder, the SLM samples from fine powder exhibited a higher corrosion potential $\left(E_{\text {corr }}\right)$ by $18.94 \%, 28.09 \%$ and $67.33 \%$ at the XY-plane, the XZ-plane and the YZ-plane, respectively. However, the corrosion current density $\left(i_{\text {corr }}\right)$ at the three cross-sections of the SLM sample from fine powder was not lower than that of the other two samples. The weight loss of the SLM sample from fine powder was the highest. These results indicated that the corrosion tendency of the SLM sample from the fine powder was the lowest, but its corrosion rate was the fastest.

Keywords: selective laser melting; stainless steel; corrosion characteristics; anodic polarization; immersion testing.

\section{$\underline{\text { FULL TEXT }}$}

(C) 2018 The Authors. Published by ESG (www.electrochemsci.org). This article is an open access article distributed under the terms and conditions of the Creative Commons Attribution license (http://creativecommons.org/licenses/by/4.0/). 